\title{
Cicatrização das feridas cirúrgicas
}

Healing of surgical wounds

Aldo Cunha Medeiros, Antônio Medeiros Dantas Filho

Revisão realizada no Departamento de Cirurgia da Universidade Federal do Rio Grande do Norte (UFRN), Brasil.

Suporte financeiro: nenhum.

Conflito de interesse: nenhum.

Correspondência: Departamento de Cirurgia - UFRN, Av. Nilo Peçanha 620, Natal, RN, Brasil, Email: cirurgex.ufrn@gmail.com

Submetido: 15 de outubro 2016. Aceito em, após revisão: 05 de dezembro, 2016.

\begin{abstract}
Background/Purpose: Wound healing has evolved from a science of clinical observation to a study of molecular biology and cellular physiology. The aim of this article is reviewing the medical literature to provide a basis for understanding the current science of wound healing. Methods: We reviewed the theme by using Pubmed and SciElo databases about healing. The phases of wound healing are the inflammatory phase, the proliferative phase, and the maturation phase. The pathway of healing is determined by characteristics of the wound on initial presentation. This knowledge is vital to select the appropriate method to treat the wound based on its ability to avoid hypoxia, infection, excessive edema, and foreign bodies.
\end{abstract} Conclusion: It is a highly complex chain of events, and surgeons' armamentarium continues to expand with methods to manage it.

Key words: Wound healing. Cell Physiological Phenomena. Molecular Biology.

\section{RESUMO}

Objetivo: A cicatrização de feridas evoluiu de uma ciência de observação clínica para um estudo de biologia molecular e fisiologia celular. O objetivo deste artigo é revisar a literatura médica para fornecer uma base para a compreensão da ciência atual da cicatrização de feridas. Métodos: Foi feita a revisão da literatura médica usando banco de dados Pubmed sobre a cicatrização. As fases de cicatrização das feridas são: fase inflamatória, a fase proliferativa e a fase de maturação. A reparação é determinada pelas características da ferida na apresentação inicial, e é vital selecionar o método apropriado para tratar a ferida com base na sua capacidade de evitar hipóxia, infecção, edema excessivo e corpos estranhos. Conclusão: Trata-se de uma cadeia altamente complexa de eventos, e o arsenal usado pelos cirurgiões continua a se expandir com métodos cada vez mais eficazes. Descritores: Cicatrização de feridas. Fisiologia celular. Biologia molecular. 
O início da cicatrização ocorre após a criação de uma ferida, definida como uma lesão corporal que normalmente envolve laceração ou ruptura de uma membrana e danos aos tecidos subjacentes. A lesão superficial pode ocorrer pela ação de agentes mecânicos ou térmicos, que levam à ruptura da pele ou de outros órgãos e danos ao tecido e sua vascularização. Em seguida ocorre o sangramento, a lesão de endotélio e o extravasamento de proteínas intravasculares e extravasculares. Este ambiente serve como um estímulo para hemostasia, inflamação e outros eventos ${ }^{1}$.

\section{RESPOSTA À LESÃo}

\section{Hemostasia}

A resolução da lesão começa com a hemostasia através da vasoconstrição e formação de coágulo, levando à cessação do sangramento. Hemostasia é conseguida através da ativação das plaquetas e da cascata de coagulação ${ }^{2,4}$.

\section{Vasoconstrição}

Ocorre imediatamente após a lesão como mecanismo de defesa principalmente contra a perda sanguínea, e dura poucos minutos. A contração do músculo liso no endotélio é a primeira resposta à lesão vascular. Vasoconstrição reflexa ocorre antes da ativação das plaquetas e da coagulação. O endotélio dos vasos danificados produz seu próprio vasoconstritor, a endotelina. Outros mediadores de vasoconstrição são derivados de catecolaminas circulantes (adrenalina), do sistema nervoso simpático (noradrenalina), além das prostaglandinas liberadas pelas células lesadas ${ }^{2} A$ ativação plaquetária contribui com estímulos adicionais para a vasoconstrição por intermédio dos mediadores bradicinina, fibrinopeptídeos, serotonina e tromboxano ${ }^{3}$.

\section{Atuação plaquetária no coágulo}

As plaquetas são as primeiras células a atuarem na resposta à lesão, na cicatrização de feridas. As plaquetas ativadas contribuem para hemostasia através 
do processo de adesão, agregação e desgranulação ${ }^{4,5}$. A agregação plaquetária no meio da matriz de fibrina forma um coágulo e o trombo impede o sangramento contínuo, estabelecendo uma barreira protetora, e fornecendo um reservatório de substâncias liberadas pela desgranulação das plaquetas. A desgranulação envolve a liberação de diversas citocinas, fatores de crescimento e de proteínas da matriz armazenada dentro dos grânulos alfa das plaquetas. Estas substâncias promovem mecanismos celulares e extracelulares importantes para hemostasia, bem como para várias outras fases da cura das feridas: deposição de matriz, quimiotaxia, proliferação celular, angiogênese e remodelamento ${ }^{3,6}$.

\section{RESPOSTA INFLAMATÓRIA (humoral e celular)}

O evento inicial quando ocorre uma ferida é um tampão de plaquetas que limita o sangramento e começa a sinalização de citocinas. Este evento inicia a cascata de coagulação e promove a amplificação e recrutamento de células para o desbridamento de tecido não viáve $\left.\right|^{5,6}$.

Após a hemostasia tem início imediato os mecanismos da inflamação. Ela se evidencia através dos sinais físicos de eritema, calor, edema e dor. No nível celular a inflamação é representada pela dilatação dos vasos, aumento da permeabilidade vascular, e recrutamento de leucócitos para o local da lesão. Duas populações de leucócitos sequencialmente dominam os eventos inflamatórios da cicatrização de feridas: neutrófilos e macrófagos. Ambos têm função crítica no desbridamento da ferida, enquanto que os macrófagos também promovem o recrutamento e ativação outras células necessárias para as etapas subsequentes na cicatrização de feridas ${ }^{5,6}$. 


\section{Reação inflamatória}

Após a lesão ocorrem:

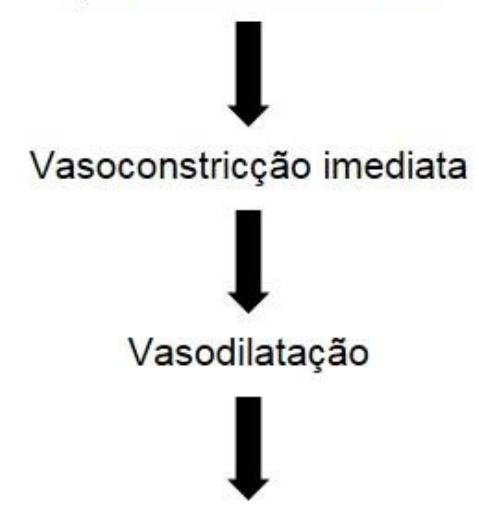

Formação de coágulo que preenche a ferida

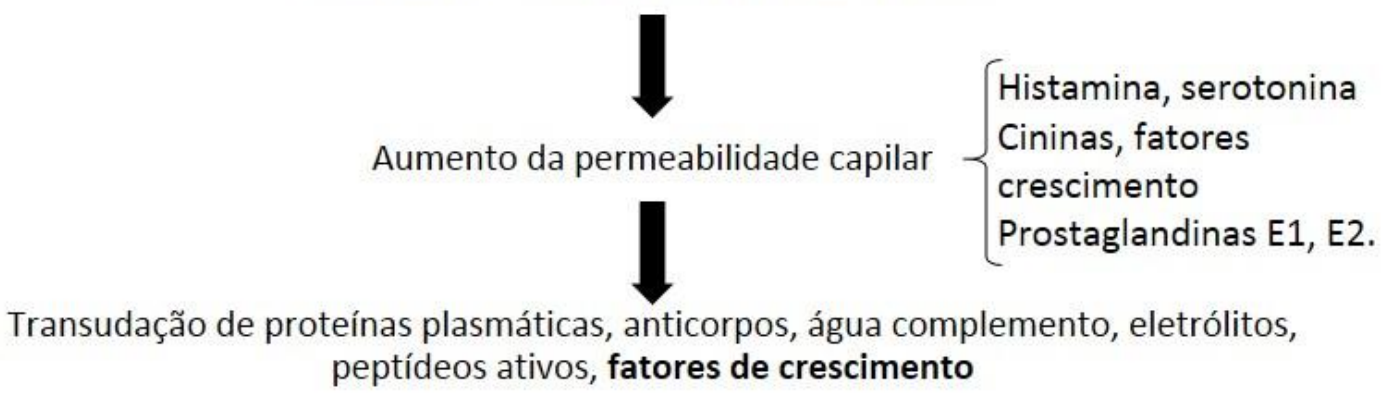

peptídeos ativos, fatores de crescimento

\section{Vasodilatação e aumento da permeabilidade}

O estabelecimento de vasoconstrição para hemostasia dura apenas minutos e em seguida vários fatores estimulam a resposta inversa que é a vasodilatação. Ela é mediada pela presença de cininas, histamina, prostaglandinas (especialmente E1 e E2) e leucotrienos ${ }^{2}$. A dilatação vascular aumenta o fluxo sanguíneo para a ferida, resultando nos sinais característicos de eritema e calor. $\mathrm{O}$ aumento do fluxo acelera a chegada de células de defesa para a lesão e a liberação de mediadores para o local da lesão. À medida que os vasos se dilatam, formamse espaços entre as células endoteliais, aumentando a permeabilidade vascular. Muitos dos mediadores liberados, entre os quais as prostaglandinas e histamina também estimulam o aumento da permeabilidade vascular. Vasodilatação em 
conjugação com o aumento da permeabilidade permitem o transporte de proteínas e componentes celulares para o espaço extravascular, de modo que 0 extravasamento de fluidos e migração das células resultam em edema da ferida ${ }^{7,8}$.

\section{Migração de leucócitos e Quimiotaxia}

Os leucócitos são submetidos ao processo ativo de diapedese, passando do espaço intravascular para chegar ao tecido lesado. As selectinas oferecem uma ligação fraca entre os leucócitos e o endotélio capilar. Ligações mais fortes são criadas entre os próprios leucócitos, as integrinas de superfície e as moléculas de adesão intercelular na superfície do endotélio². A migração celular da superfície endotelial para o espaço extravascular das feridas é mediada por numerosos fatores químicos, fenômeno conhecido como quimiotaxia. Agentes quimiotáxicos podem incluir fatores de complemento, histamina, produtos bacterianos, prostaglandinas, leucotrienos e fatores de crescimento. Estas substâncias atraem neutrófilos, macrófagos e linfócitos para o local da inflamação ${ }^{8-10}$.

Participação das células na reação inflamatória

Migração de granulócitos neutrófilos

(destruição enzimática da fibrina)

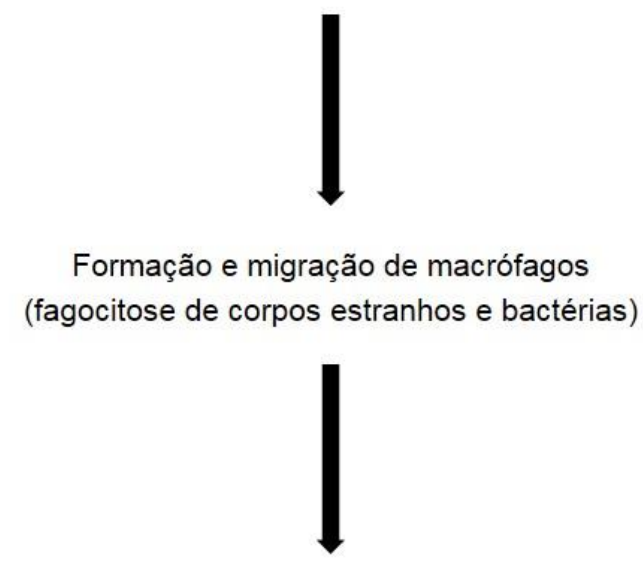

Aparecimento de fibroblastos

(formação de colágeno) 


\section{Neutrófilos}

Os neutrófilos são o primeiro subconjunto de leucócitos a entrar na ferida. Estimulados por prostaglandinas, complemento, interleucina-1 (IL-1), fator de necrose tumoral alfa (TNF-a), fator de crescimento transformador-beta (TGF- $\beta$ ) e produtos bacterianos, os neutrófilos chegam ao local da lesão em grandes números no prazo de 24 a 48 horas após a ocorrência da lesão ${ }^{3-5}$. Neste período, os neutrófilos podem constituir até $50 \%$ de todas as células presentes na ferida. As principais funções de neutrófilos são defender a ferida de bactérias e remover restos de tecidos. Os neutrófilos liberam vários tipos de enzimas proteolíticas, fragmentando as bactérias. Restos de bactérias e de tecidos são removidos da ferida pela fagocitose dos neutrófilos. Além de proteases, os neutrófilos produzem radicais livres reativos de oxigênio, que se combinam com o cloro para tornar as feridas menos susceptíveis às bactérias ${ }^{7}$. O papel secundário de neutrófilos é manter a fase inicial do processo inflamatório através da excreção de citocinas ${ }^{3,4}$. Uma citocina de particular importância é o TNF- $\alpha$. TNF- $\alpha$ amplifica quimiotaxia de neutrófilos e estimula macrófagos, queratinócitos, fibroblastos e expressão de fatores de crescimento necessários na angiogênese e síntese de colágeno ${ }^{3}$. Com o tempo, os neutrófilos são eliminados da ferida por apoptose ou são fagocitados pelos macrófagos.

\section{Macrófagos}

Após 48 a 96 horas após o ferimento, os leucócitos predominantes nas feridas são os macrófagos. Derivados de monócitos extravasados, os macrófagos são essenciais para cicatrização de feridas. Eles executam diversas tarefas ao longo de ambos os processos inflamatórios e na fase proliferativa da cicatrização de feridas. Os macrófagos, da mesma maneira que os neutrófilos, removem da ferida detritos através da fagocitose e secreção de proteases. Servindo como uma fonte primária de diversas citocinas e fatores de crescimento, os macrófagos são necessários para apoiar o recrutamento e ativação celular, a síntese da matriz extracelular, a angiogênese e a remodelação. Estimulam a formação de fibroblastos, a síntese do colágeno pelos fibroblastos e a neoformação de vasos 
sanguíneos na ferida. Ao contrário dos neutrófilos, os macrófagos permanecem dentro de um ferimento até a sua cura completa ${ }^{2,3,8,11}$.

\section{Funções dos macrófagos na cicatrização8:}

- Fagocitose;

- Produção de citocinas (FCF, FCE, FCDP etc);

- Estimulam a formação de fibroblastos;

- Estimulam a síntese do colágeno;

- Estimulam a neoformação vascular.

\section{Linfócitos}

Os linfócitos são atraído ao local da lesão pela interleucina-2 (IL-2) e outros fatores. Na segunda semana, os linfócitos representam o tipo predominante de leucócitos na ferida. São considerados críticos para as fases inflamatória e proliferativa da reparação. Além de fornecer imunidade celular para a produção de anticorpos, os linfócitos atuam como mediadores dentro do ambiente da ferida através da secreção de linfocinas e estimulam o contato célula a célula entre linfócitos e fibroblastos. Os detalhes de como os linfócitos contribuem para a cicatrização não são totalmente conhecidos ${ }^{2,6,7}$.

\section{Mastócitos}

Os mastócitos podem alcançar um aumento cinco vezes maior em número no local da lesão. Grânulos do citoplasma dos mastócitos contêm histamina, citocinas (TNF- $\alpha$ ), prostaglandinas e protease. A sua desgranulação leva ao aumento da permeabilidade vascular, ativação celular, deposição de colágeno, e remodelação dos tecidos em cicatrização $0^{2,8}$.

\section{FASE PROLIFERATIVA}

Os eventos da inflamação de levam ao desbridamento e limpeza da ferida. Uma vez desbridada, a cicatrização das feridas entra em uma etapa conhecida como fase proliferativa de reparação. A proliferação ocorre no período de 4 a 12 
dias pós-lesão. Durante este período, fibroblastos, células musculares lisas, células endoteliais e células epiteliais começam a cobrir o local da lesão. Essas células restabelecem a continuidade do tecido através da deposição da matriz, angiogênese e epitelização ${ }^{2,3,8}$.

\section{Fibroplasia e fibroblastos}

Os fibroblastos são uma das últimas células a surgir na ferida (Figura 1). Eles são mobilizados para o local da lesão por produtos das linhagens celulares que vieram antes deles. Os primeiros sinais para o recrutamento de fibroblastos vem de produtos derivados de plaquetas: fator de crescimento derivado de plaquetas (PDGF), fator de crescimento insulin-like (IGF-1) e fator de crescimento epitelial. Macrófagos e fibroblastos liberam inúmeros fatores de crescimento e citocinas que contribuem para a migração de fibroblastos: fator de crescimento fibroblástico (FGF), IGF-1, fator de crescimento endotelial vascular (VEGF), IL-1, IL-2, IL-8, PDGF, fator de crescimento transformador- $\alpha$ e $\beta$ (TGF- $\alpha$, TGF- $\beta$ ) e TNF- $\alpha$ 8,9,14. Destas substâncias, PDGF é o mais potente fator de fibroblastos quimiotático e mitogênico, estimulador da migração dos fibroblastos e a síntese de colágeno por essas células ${ }^{2}$. Há uma segunda população de fibroblastos que residem dentro da ferida. Eles proliferam menos, sintetizam mais colágeno e se transformam em miofibroblastos, envolvidos na contração da matriz extracelular. Para exercer a contração das feridas, os miofibroblastos são ricos em actina e miosina, proteínas responsáveis pela contração muscular². 


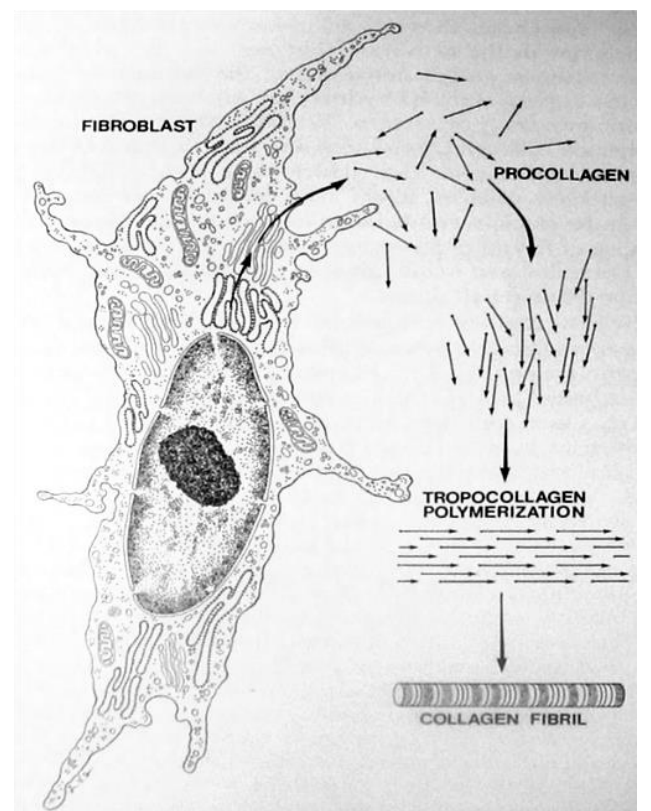

Figura 1 - Esquema de fibroblasto sintetizando colágeno inicialmente sob a forma de procolágeno, que se transforma em tropocolágeno, polimeriza-se e forma fibras ${ }^{16}$.

\section{Matriz extracelular}

Além de mediar a fibroplasia, os fatores de crescimento PDGF e TGF- $\beta$ desempenham um papel importante na matriz extracelular. Ambos estimulam a produção de fibroblastos na matriz. A matriz consiste de monômero de colágeno produzidos por fibroblastos, proteoglicanos e fibronectina ${ }^{9}$. Juntas, essas substâncias restabelecem a continuidade do tecido conjuntivo entre as bordas da ferida. Quando a matriz é criada, TGF- $\beta$ também tem função importante no restabelecimento da estabilidade estrutural do tecido cicatricial, aumentando a produção de proteínas de adesão celular ${ }^{10,11}$.

\section{Síntese de colágeno e Proteoglicanos}

Colágeno, a proteína mais abundante no organismo, existe em pelo menos 20 subtipos $^{12}$. Dois subtipos são importantes para a reparação da ferida (Figura 2). Colágeno tipo I predomina na matriz extracelular da pele intacta. Colágeno tipo III, presente em menor quantidade na pele intacta, torna-se mais capital no processo de cicatrização de feridas, especialmente na fase inicial da cicatrização. A síntese de colágeno começa horas após o ferimento, mas ela não se torna significativa até 
aproximadamente uma semana após a lesão. A ativação dos fibroblastos para sintetizar o colágeno é derivada de fatores de crescimento e das próprias condições metabólicas da ferida ${ }^{7}$. A estrutura da molécula do colágeno é formada por três hélices de cadeias polipeptídicas, inicialmente denominada protocolágeno, com cerca de 1000 aminoácidos. Ao entrar no retículo endoplasmático, o tropocolágeno sofre hidroxilação e glicosilação. O processo de hidroxilação dos principais aminoácidos do colágeno, prolina e lisina, exige a presença de co-fatores (oxigênio e ferro), co-substrato ( $\alpha$-cetoglutarato), e um doador de elétron (ácido ascórbico) ${ }^{2}$. O procolágeno é acondicionado dentro do complexo de Golgi dos fibroblastos e exportado para a matriz extracelular. Dentro do espaço extracelular, uma procolágeno-peptidase cliva as extremidades das cadeias, permitindo que haja a polimerização ${ }^{3}$. Além do colágeno, os fibroblastos produzem e secretam glicosaminoglicanos. Normalmente, glicosaminoglicanos se unem às proteínas para formarem os proteoglicanos, considerados um dos componentes principais do tecido de granulação, tendo uma função de apoio para a formação de fibrilas de colágeno ${ }^{11}$.
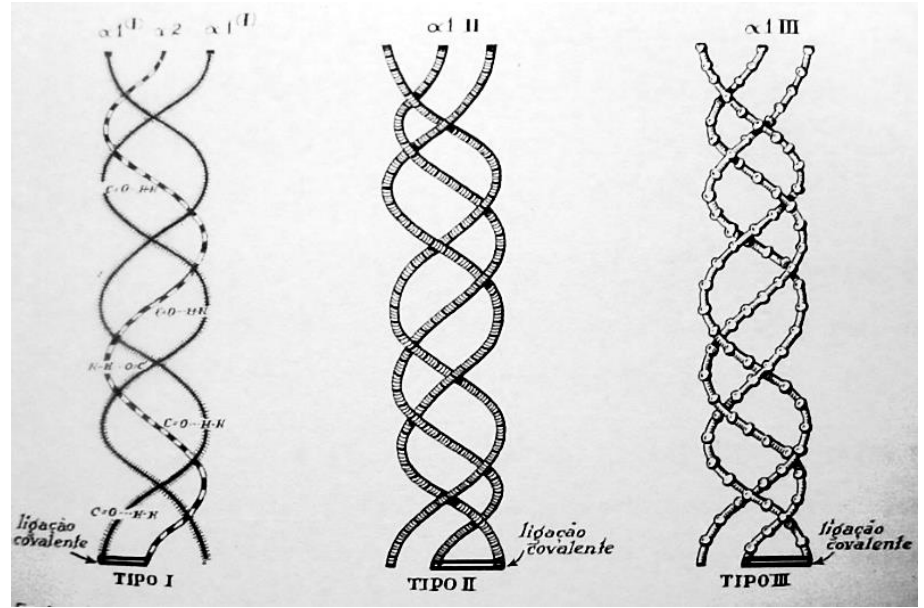

Figura 2 - Principais moléculas do colágeno. O colágeno tipo III predomina na cicatriz jovem e o tipo I na cicatriz mais resistente, mais tardia, após a ocorrência da remodelagem ${ }^{16}$.

\section{Angiogênese}

A lesão vascular decorrente da ferida desencadeia o processo de reparação via angiogênese ${ }^{9}$. A angiogênese começa nos primeiros 1 a 2 dias após a lesão 
vascular e pode tornar-se evidente em cerca de 4 dias após a lesão. As células endoteliais de vênulas intactas migram da periferia para a borda da ferida e novos capilares são formados ${ }^{13}$. Nas feridas fechadas, neovasos de bordas opostas coalescem para revascularizar a ferida. Ao contrário de feridas fechadas, os novos capilares de uma ferida aberta fundem-se e crescem na mesma direção, o que contribui para a formação do tecido de granulação ${ }^{7}$. Os eventos da angiogênese são regulados por meio de fatores de crescimento (TNF-a, TGF-b, VEGF, FGF, PDGF) derivados de plaquetas, macrófagos e células endoteliais danificadas ${ }^{13}$. Além destes mediadores, o ambiente metabólico da ferida influência a angiogênese. Em condições de isquemia, o aumento de lactato, juntamente com a diminuição do pH e oxigênio contribuem para a inibição da angiogênese9,14.

\section{Tecido de granulação}

É um tecido inflamatório jovem, vermelho, muito vascularizado, formado por:

Água, proteínas, células inflamatórias, fibroblastos, colágeno, citocinas, complemento, glicoproteínas, proteoglicanos, fibrina, neovasos em grande quantidade ${ }^{11-15}$.

Durante 0 processo de cicatrização ele sofre 0 processo de REMODELAGEM, quando ocorrem os seguintes fenômenos:

- Reabsorção de glicoproteínas, albumina, globulinas;

- Degradação dos proteoglicanos (ácido hialurônico, fibronectina, etc);

- Reabsorção de água e eletrólitos;

- Passa a predominar o colágeno tipo I (80\%); o tipo III participa com (20\%).

\section{Epitelização}

No mesmo modo que a angiogênese, a restauração do epitélio começa precocemente no processo de cicatrização, mas não é facilmente perceptível até vários dias após a lesão. A epitelização restabelece a barreira externa que minimiza as perdas de líquidos e a invasão bacteriana. O processo de epitelização começa com espessamento da epiderme ao longo das bordas da ferida ${ }^{2,13}$. As células 
basais nas margens da ferida de alongam, emitem prolongamentos à semelhança de pseudópodes, e os hemidesmossomos que as unem são desfeitos, bem como a laminina da camada basal, permitindo a migração das células epiteliais ${ }^{2}$. Os movimentos migratórios são facilitados pela expressão de novas integrinas na superfície celular. A produção de actinomiosina nos miofibroblastos, que induzem o mecanismo de contração das feridas, também contribui para a progressão de células através da ferida em cicatrização ${ }^{13}$. As células epiteliais são capazes de secretar metaloproteinase para quebrar a fibrina, facilitando o processo de migração celular. (Figura 3). O movimento das células basais ocorre paralelamente à orientação das fibras de colágeno presentes na ferida, fenômeno conhecido como "guia por contato". As células epiteliais continuam a proliferar e migrar até que encontrem as células da borda oposta da ferida, quando é concluído o fenômeno migratório². Uma nova camada de epitélio é criada e as células se diferenciam, transformando de células alongadas em cuboidais, com aparência de células basais, quando novamente são unidas através de hemidesmossomos na membrana basal da pele. Proliferação celular subsequente leva ao restabelecimento da epiderme com múltiplas camadas celulares ${ }^{2}$. Os eventos da epitelização são influenciados por sinalizações intercelulares, fatores do crescimento e pelas condições metabólicas intrínsecas da própria ferida. A baixa tensão de oxigênio que ocorre após a lesão estimula a produção de TGF- $\beta$, que ajuda a diferenciação das células epiteliais permitindo a migração e mitogênese. $O$ TGF- $\beta$ e o fator de crescimento de queratinócitos (KGF) estimulam diretamente a replicação celular. Em uma etapa posterior, o contrário ocorre quando há a angiogênese: a elevada tensão de oxigênio estimula a diferenciação de células epiteliais, para completar os eventos da epitelização $0^{7,13,14}$. 


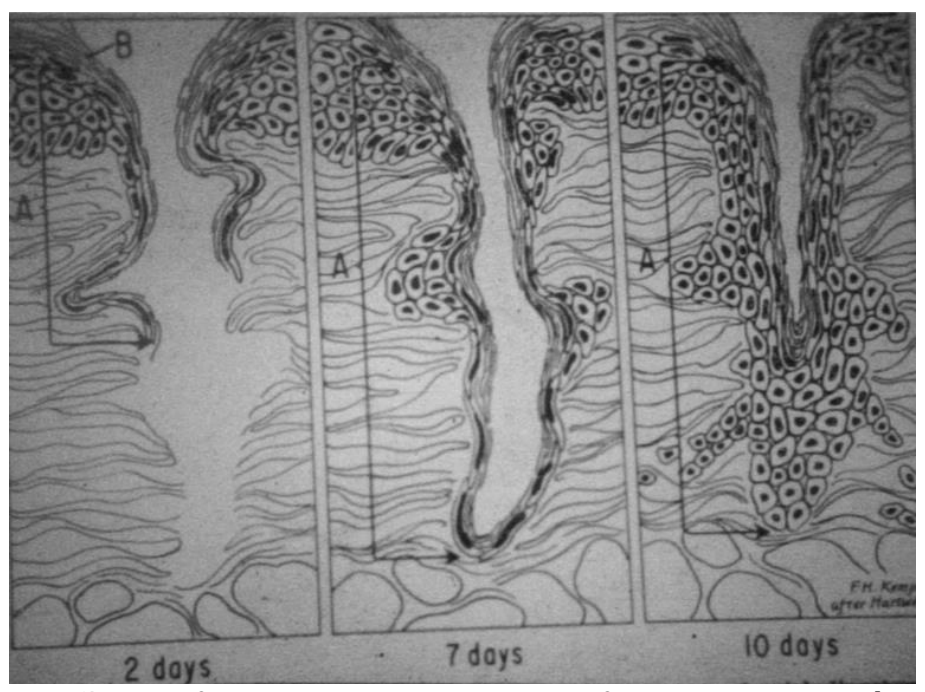

Figura 3 - Epitelização de ferida: observa-se na figura esquemática a migração de células epiteliais da superfície para a profundidade da ferida e em seguida a proliferação dessas células até a superfície, até fechá-la ${ }^{16}$.

\section{Funções da epitelização}

- Proteção das feridas contra bactérias;

- Proteção contra agentes físicos e químicos;

- Proteção contra perda de líquidos e eletrólitos;

- Efeito estético;

- Vedação de anastomoses digestivas.

\section{A maturação do colágeno}

O último e mais longo fenômeno de cicatrização da ferida é a maturação do colágeno, iniciando na primeira semana após a lesão, continuando por 12 a 18 meses. Durante este período, a matriz de colágeno continuamente sofre reabsorção e deposição no processo de remodelação. A matriz inicial de colágeno difere em conteúdo e organização daquela do tecido normal, não lesado. A matriz de colágeno da ferida jovem contem de $20 \%$ de colágeno tipo III, o que torna essa matriz muito frágil. Além disso, as fibrilas de colágeno da matriz são altamente glicosiladas e finas. Elas são dispostas paralelamente e não se entrelaçam. Após uma semana de evolução, a resistência da ferida atinge apenas 3\% daquela do tecido normal. As colagenases e proteinases degradam as fibrilas de colágeno jovem e novo colágeno continua sendo depositado pelos fibroblastos ${ }^{2,11,15}$. 


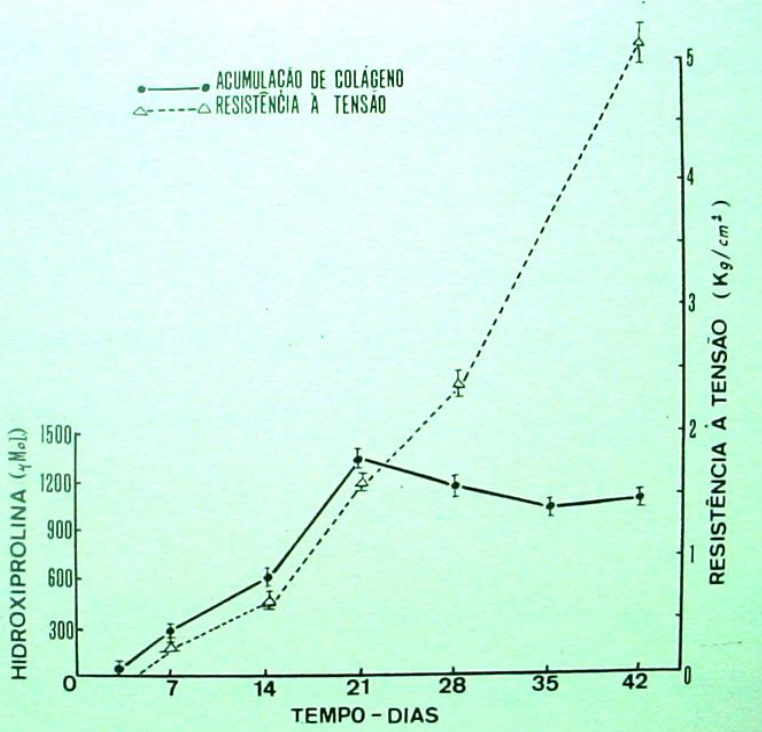

Figura 4 - A figura demonstra que após o 21ํ dia de cicatrização, (em trabalho experimental em ratos), a resistência das feridas continua aumentando e a produção de colágeno (hidroxiprolina) estabiliza. Neste momento, começa a maturação do colágeno com formação de ligações covalentes cruzadas intra e intermoleculares, e o fenômeno prossegue por muito tempo ${ }^{16}$.

Esse novo colágeno tem fibras mais espessas, resistentes e mais organizadas, quando a lisil-oxidase promove a ligação cruzada entre as fibras de colágeno. No processo de maturação de fibrilas de colágeno solúveis se transformam em colágeno insolúvel, altamente resistente. São as ligações químicas covalentes cruzadas as responsáveis diretas pela maturação ${ }^{11}$. Elas ocorrem progressivamente, principalmente nas cadeias laterais de dois aminoácidos, prolina e lisina, após sofrerem hidroxilação. São então formadas ligações covalentes inter e intramoleculares complexas e estáveis, com a participação da hidroxila desses aminoácidos (Figura 4). Para que haja maturação do colágeno é indispensável a presença de ácido ascórbico (vitamina C), oxigênio e ferro, que são cofatores da hidroxilação da prolina e lisina ${ }^{11}$.

Passados cerca de 20 dias, no processo denominado remodelagem do tecido de granulação, o conteúdo de colágeno tipo I passa a 80\% e de colágeno tipo III 20\%. Após cerca de 3 semanas, a resistência da ferida aumenta em 30\%. Após 3 meses, atinge $80 \%$ da resistência do tecido original ${ }^{10}$. As feridas cicatrizadas não atingem a mesma resistência do tecido original. A capacidade de se aproximar da 
resistência máxima, próxima do tecido original, depende do tamanho da ferida, da profundidade, localização e tipo de ferida (traumática ou cirúrgica), do estado nutricional (albuminemia, vitamina C, vitamina A), dos cuidados no tratamento das feridas e da saúde geral dos indivíduos. A compreensão da fisiopatologia da cicatrização das feridas é crucial para o cirurgião. Limitações intrínsecas e extrínsecas dos pacientes afetam cada fenômeno desse processo complexo, de modo que entender bem sua biologia pode influenciar o tratamento bem sucedido das feridas cirúrgicas e também das traumáticas ${ }^{15}$.

\section{REFERÊNCIAS}

1. Medeiros AC. Conceituação da cicatrização das feridas cirúrgicas. Rev Saúde. 1992; 7(2):9-20.

2. Childs DR, Murthy AS. Overview of Wound Healing and Management. Surg Clin North Am. 2017;97(1):189-207.

3. Efron DE, Chandrakanth A, Park JE, et al. Wound healing. In: Brunicardi C, Andersen DK, Billiar TR, editors. Schwartz's principles of surgery. 8th edition. New York: McGraw-Hill; 2005.

4. Schmaier A. The elusive physiologic role of Factor XII. J Clin Invest. 2008;118:3006-9.

5. Furie B, Furie C. Mechanisms of thrombus formation. $\mathrm{N}$ Engl $\mathrm{J}$ Med. 2008;359:938-49.

6. Rozman P, Bolta Z. Use of platelet growth factors in treating wounds and softtissue injuries. Acta Dermatovenerol Alp Panonica Adriat. 2007;16(4):15665.

7. Hunt TK. Wound healing. In: Doherty GM, Way LW, editors. Current surgical diagnosis and treatment. 12th edition. New York: McGraw-Hill; 2006.

8. Eming SA, Krieg T, Davidson JM. Inflammation in wound repair: molecular and cellular mechanisms. J Invest Dermatol. 2007;127:514-21.

9. Schugart RC, Friedman A, Zhao R, et al. Wound angiogenesis as a function of oxygen tension: a mathematical model. Proc Natl Acad Sci U S A. 2008;105:2628-33.

10. Broughton $\mathrm{G}$, et al. The basic science of wound healing. Plast Reconstr Surg. 2006;117(7S):12S-34S.

11. Diegelmann RF. Cellular and biochemical aspects of normal wound healing: an overview. J Urol. 1997;157(1):298-302.

12. Adams CA, Biffi WL, Cioffi WG. Wounds, bites and stings. In: Feliciano DV, Mattox KL, Moore EE, editors. Trauma. 6th edition. New York: McGraw-Hill; 2008.

13. Raja SK, Garcia MS, Isseroff RR. Wound re-epithelialization: modulating keratinocyte migration in wound healing. Front Biosci. 2007;12:2849-68. 
14. Werner S, Grose R. Regulation of wound healing by growth factors and cytokines. Physiol Rev. 2003;83:835-70.

15. Reinke JM, Sorg H. Wound repair and regeneration. Eur Surg Res. 2012;49: 35-43.

16. Medeiros AC. Cicatrização dos tendões planos do abdome após vários processos de sutura. Estudo experimental. Tese de doutorado, Universidade Federal do Rio de Janeiro, 1980. 